ROCZNIKI PSYCHOLOGICZNE/ANNALS OF PSYCHOLOGY

2020, XXIII, 3, 247-266

DOI: https://doi.org/10.18290/rpsych20233-4

TOMASZ KORULCZYK ${ }^{\mathrm{a}}$

HELENA D. COOPER-THOMAS ${ }^{b}$

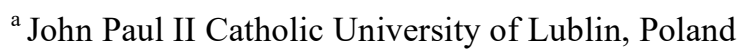

${ }^{\mathrm{b}}$ Auckland University of Technology, New Zealand

\title{
PERSON-SUPERVISOR FIT AND PROACTIVE BEHAVIOR AND UNETHICAL BEHAVIORS
}

This study examined how person-supervisor fit is related to employees' proactive behavior and unethical behavior towards the organization. The study involved 321 employees representing various sectors in Poland. The participants completed the Person-Supervisor Fit Scale, Proactive Behavior Scale, and the Unethical Behavior Questionnaire. Results show that a supplementary fit is weakly and positively related to proactive behavior but is not related to complementary fit. Surprisingly, supplementary fit is weakly but positively related to unethical behavior, while complementary fit from a needs-resources perspective is weakly and negatively associated with unethical behavior. Conclusions may be applied to organizational settings challenged by the problem of employee unethical behavior and their low proactivity in the context of person-supervisor congruence.

Keywords: person-supervisor fit; supplementary fit; complementary fit; unethical behavior; proactive behavior.

Correspondence concerning this article can be sent to TOMASZ KorUlczYK, PhD, Institute of Psychology, The John Paul II Catholic University of Lublin, Al. Racławickie 14, 20-950 Lublin, Poland; e-mail: tomasz.korulczyk@gmail.com; ORCID: https://orcid.org/0000-0002-5182-5702; HELENA D. COOPER-ThOMAS, ORCID: https://orcid.org/0000-0003-4080-9704. 
The idea of person-environment fit (PE fit) appeared in psychology in the first decades of the 20th century (Lewin et al., 1935; Parsons, 1909). Since then the conceptualization of PE fit has developed, including a relatively the new area of relational fits based on personal character: person-supervisor fit (PS fit). Research on PS fit has advanced rapidly over the last 15 years. However, as with any abundant research area, differences have arisen in definitions, conceptualizations and operationalizations of PS fit (Brudek et al., 2018; Korulczyk, 2016; Kristof-Brown \& Billsberry, 2013; Schneider et al., 1999; Schwab, 1980).

According to the over-arching paradigm of person-environment fit (PE), attitudes and behaviors result from the compatibility between the attributes of person and environment (Czerw \& Czarnota-Bojarska, 2016; Endler \& Magnusson, 1976; Schneider, 1987). In line with our study's focus on organizational settings, scholars have drawn from the PE fit paradigm to predict a wide range of outcomes for employees, including the types of companies they select to join (Cable \& Judge, 1996; Turban \& Keon, 1993), the stress they experience, and their work satisfaction (Edwards, 1991), to their intention to quit (O'Reilly et al., 1991), and a complete range of organizational behaviors: innovative, counter-productive, proactive, unethical, and civic (Dalal, 2005; De Coninck, 1992; Hammond et al., 2011; Thomas et al., 2010). PS fit (alongside person-organization fit and personjob fit) is a specific mental representation of the relationship between the employee and his supervisor (organization-PO fit or work-PJ fit) which affects the level of motivation of the employee. The willingness to get involved, to strive to the best possible quality or readiness to take action for the organization result from high PS fit (Czerw \& Czarnota-Bojarska, 2016).

PS fit is not the only representation that can significantly affect the level of motivation and employee behaviors like proactive or unethical behavior, but in this study we attempt to answer the question to what extent PS fit is able to explain these behaviors in light of other well-researched representations like PO fit. Studies show that in most cases the higher the perceived fit, the greater the positive impact on employee motivation and in consequence, positive outcomes (Czerw \& Czarnota-Bojarska, 2016).

We have chosen two extreme types of organizational behavior, of which proactive can be considered an example of positive and unethical of negative behavior. Taking under consideration that above types of organizational behaviors represent only a small part of all potential types of behavior, we are particularly interested in proactive behavior due to its importance at the early stage of employee stay in the organization-in employee socialization (Saks et al., 2011), 
and unethical behavior which plays an important role in the subsequent stages of staying in the organization.

There are few papers in the literature investigating PS fit, proactive behavior or unethical behaviors together, mainly because PS fit is a relatively new concept. The first mention of supervisor-subordinate similarity appeared in Turban $\&$ Jones (1988). Further, at the 17th Annual Conference of the Society for Industrial and Organizational Psychology in Toronto, Smith (2002) introduced the term "subordinate-supervisor fit." Three years later, in their meta-analysis, Kristof-Brown et al. (2005), formulated the term person-supervisor fit, which is widely used and quoted today.

Reports from current studies indicate that the effect size between PS fit and proactive behavior is relatively low. It has been proven in the Chinese population (Zhang et al., 2012). Another study shows that PS fit is weakly and positively associated with organizational behavior (Kim \& Kim, 2013), which, as the literature shows, is associated with proactive behavior. PS fit is also weakly and positively linked with moral competence, which is something opposite to unethical behavior (Kim \& Kim, 2013). Some studies show a positive and weak association between person-organization fit (which is a more general form of PE fit) and ethical intent (Ruiz-Palomino \& Martínez-Cañas, 2014) being considered as a proxy for ethical behavior (Ajzen \& Fishbein, 1980), something directly opposite to unethical behavior. Due to the lack of research, it is difficult to clearly determine the strength of the PS fit and proactive behavior or unethical behavior relationships on the Polish population.

Studying above-mentioned concepts may be particularly interesting in the context of socio-cultural transformations that took place in Poland during the transition from communism to capitalism in the 1990s and its consequences. In comparison to other cultures-although the relations occurring in the organization are now similar to those in Western cultures - for over 50 years of the last century they were shaped by a strongly hierarchical model of supervisorsubordinate relations in state-owned plants. Thus, we expect PS fit relationships with outcome variables to be stronger than in other cultures, but they may have different nature and specificity than other cultures.

From an applied perspective, despite many years of research into unethical behavior, organizations continue to face unethical behavior of their employees, which costs organizations a significant amount of their financial resources (McNeill, 2019) and cannot successively apply the results of literature research 
to reduce consequences of this type of conduct. It would be interesting to investigate what role PS fit plays in its occurrence.

In conclusion, there are many arguments supporting the value of undertaking the study of PS fit and its outcomes. The aim of the study is to increase the current knowledge in this field.

\section{THEORETICAL BACKGROUND}

\section{Person-Supervisor Fit}

Fit concepts do not have a uniform and clear theoretical basis, such as wellestablished intelligence theories. They are based on the ideas of various researchers who emphasize certain aspects of the fit as being important. The foundations for the fit theories were laid by the interactionists, because fit between two subjects cannot exist without first recognizing that these two subjects are both sides of the interaction; also by the General Systems Theory (Laszlo, 1996; Von Bertalanffy, 1968) as fit concepts can be captured and well described within a systemic approach because each type of fit is an element of the system, with individual links and interactions; the job demands-resources theory (Bakker \& Demerouti, 2007; Llorens et al., 2006) because it emphasizes the major role of balance between available resources and existing demands, especially in the development of the concept of complementary fit.

In our article PS fit was defined as occurring when a subordinate has similar characteristics or supplements the characteristics of a superior (Korulczyk, 2016). Fit can occur at the level of values, goals, personality traits, and attitudes (Caplan, 1987; Edwards, 1991; Korulczyk \& Korulczyk, 2018; Kristof, 1996). PS fit derives from the theory of person-organization fit introduced by (Kristof, 1996), where there are two main types of fit: supplementary and complementary. Then, there are two subtypes of complementary fit: demands-abilities and needs-supplies fit (see Caplan, 1987; Edwards, 1991). A supplementary fit occurs when there is a similarity between the essential characteristics of a superior and a subordinate (Kristof, 1996). These are personalities, values, goals and attitudes. A complementary demands-abilities fit occurs when the requirements of the supervisor can be satisfied by the abilities of the subordinate, as well as when the abilities of the subordinate are reflected in the demands of the supervisor (Caplan, 1987). Both the requirements of the superior and the abilities of the subordinate are expressed in terms of time, effort, commitment, experience, 
knowledge, skills and predispositions. A complementary match from the perspective of needs (subordinate) and resources (superior). Fit occurs when the needs of the subordinate are satisfied by the capabilities of the superior, but also when the capabilities of the superior are sufficient to meet the needs of the subordinate. Both needs and resources are included in the following categories: financial, physical, psychological, social, developmental. It should be noted, however, that most of the PS fit literature conceptualizes PS fit solely as supplementary fit (Czerw \& Czarnota-Bojarska, 2016).

The main theoretical framework of supplementary fit is provided by the similarity-attraction hypothesis (Byrne, 1971), which states that people are more attracted to those with whom they are similar. It may be expressed in a form of a systematic tendency to more favorably evaluate and to like those whom they perceive as being more rather than less similar to themselves (Byrne, 1971; Wayne \& Liden, 1995). Also, Festinger's theory of social comparison, and Heider's balanced state theory, play their roles in explanation of the mechanism of supplementary fit as it suggest that people have a fundamental need for consensual validation of their perspectives, which can be met by interacting with similar others (Kristof-Brown et al., 2005). The theoretical framework for complementary demands-abilities fit is provided by the job demands-resources model (Bakker \& Demerouti, 2007), while for complementary needs-supplies fit by theories of need fulfilment (e.g., Locke, 1976; Rice et al., 1985). These theories share the common proposition that people will experience more positive job attitudes when their needs are satisfied (Kristof-Brown et al., 2005).

\section{Proactive Behavior}

Proactivity has been conceptualized in the literature in many ways (Crant, 2000; Saks, Taggar, \& Ashforth, 2004). In an integrative approach it is defined (Crant, 2000) as "taking initiative in improving current circumstances... [and] challenging the status quo rather than passively adapting to present conditions" (p. 436). In a similar vein, proactive behavior is described as being anticipatory, self-initiated, and taking responsibility for effecting change (Parker et al., 2010; Parker \& Collins, 2010). The concept of personal initiative is closely associated with proactive behavior that is self-starting, persistent, and proactive with a view on the future (Frese \& Fay, 2001). The definitions of proactive behavior appearing in the literature also include active effort to consciously influence his or her 
new surroundings, active gathering information on the task, role, group, and organization through personal initiatives (Parker et al., 2006).

The common theme binding the above conceptualizations is taking an active role in creating more favorable work conditions, and it applies to the following behaviors: feedback-seeking, information-seeking, networking, general socializing, positive framing, relationship building, observation and modelling, and listening (Ashford \& Black, 1996). This is contrary to a reactive pattern of behavior and passive response to information and opportunities provided by the organization (Bateman \& Crant, 1993). There is evidence that PS supplementary fit is positively related to proactive personality, proactive behavior, and organizational citizenship behavior in various cultures (Kim \& Kim, 2013; Zhang et al., 2012), which, as the literature shows, is associated with proactive behavior. Based on the above we formulated the following hypothesis:

\section{Hypothesis 1:}

PS supplementary fit is positively associated with proactive behavior

Literature shows that employees who feel that their abilities match the job demands and needs become more engaged (Wang et al., 2017). Also, for high proactive personality employees, supplementary fit (in terms of values) with the work team can enhance complementary fit (Seong et al., 2015). By analogy we conclude that supplementary fit with the supervisor can also enhance complementary fit, as in the case of workgroup because PS fit is classified to be a relational type like PG fit (Oh et al., 2014). Based on the above we formulated this hypothesis:

\section{Hypothesis 2:}

PS complementary fits are positively associated with proactive behavior

\section{Unethical Behaviors}

There are many theories on the issue of employee unethical behavior. First, the contingency model for measuring ethical decision making (Ferrell \& Gresham, 1985) proposed that a person's eagerness to behave unethically depends on several factors: (1) possessed values and attitudes by the employee; (2) the ethical dilemma confronted by the person; (3) some organizational factors such as the pressure to achieve results; (4) the opportunity to engage in unethical behavior; and (5) the values and attitudes of members of the person's social 
group. The valuable contribution of this theory to the explanation of unethical behaviors is to point out the fact that the appearance of such a behavior is not only the result of the person's own characteristics, but also of external factors.

Second, a general theory of marketing ethics (GTME; Hunt \& Vitell, 1986). GTME offers an interesting decisional perspective in explaining unethical behaviors-it attempts to explain how an individual makes a decision when confronted with an ethical problem. According to GTME, the perceived ethical problem, the perceived alternative to solving the ethical problem, and the perceived consequences of the person's behavior are influenced by environmental factors and his or her personal experiences (Hunt \& Vitell, 1986). Also, ethical judgments are a function of deontological evaluations (where the individual evaluates the inherent righteousness of a behavior) and teleological evaluations (where the consequences of the behavior are evaluated by the individual). It is assumed that ethical judgments influence how a person behaves when confronted with an ethical problem. The consequences of the person's behavior influence the personal response to an ethical problem in the future (De Coninck, 1992). The research methodology is based on the above-mentioned approaches to unethical behavior in this study.

Literature reports support the view that PE fit and its subtypes are related to ethical behavior. For instance, Ruiz-Palomino \& Martínez-Cañas (2014) proved that PO fit is positively associated with ethical intent. Also, Kim and Kim (2013) provided evidence that moral competence is associated with PS supplementary fit. Supervisors gain greater acceptance from subordinates if they are more appreciative of their leaders' moral competence, or if supplementary fit is higher than lower. By analogy we assume that people who share similar values to superiors might be less ethical, especially if the highest evaluated values are the result of focus rather than compliance with rules (Karassavidou \& Glaveli, 2006). On this basis, the following hypothesis is formulated:

\section{Hypothesis 3:}

\section{PS supplementary fit is negatively associated with unethical behavior}

Supervisors with a high level of supplementary fit with their subordinates have a better understanding of what subordinates want and need in conducting their jobs (have better complementary fit) - due to better communication between them than for those employees with low similarity (Meglino \& Ravlin, 1998) and they are more likely to satisfy these needs. For this reason, we assume 
that when a subordinate's needs are satisfied, they are less likely to behave in unethical way. On this basis, we hypothesize the following:

\section{Hypothesis 4:}

PS complementary fits are negatively associated with unethical behavior

\section{METHOD}

\section{Sample and Procedure}

Based on the sample size calculator, it was determined that the sample should include optimally 543 people. ${ }^{1}$ Finally, 500 people were invited with 335 participating (67\% response rate). 7 respondents were excluded as they returned severely incomplete questionnaires $(2.1 \%)$. As a result, our sample consists of 328 employees, with a slight prevalence of women (63\%, W: 207, M: 121). The average age is 31.93 years $(S D: 11.09)$, ranging from 19 to 63 years. The majority of respondents live in large cities $(55 \%, 181)$ or rural areas $(27 \%, 90)$. Education of employees is master's degree $(19 \%, 63)$, undergraduate $(8 \%, 27)$, high school $(20 \%, 67)$, incomplete secondary education $(2 \%, 5) ; 51 \%$ did not report their education. The majority were specialists $(52 \%, 168)$, interns $(22 \%, 73)$, managers and executives $(12 \%, 40)$, qualified workers $(10 \%, 31)$, unqualified workers $(4 \%, 16)$.

The research was conducted between October 2015 and April 2016 using paper-pencil survey method. The first part of the survey asked for demographic variables such as gender, age, occupation, position, work record, socio-economic status. The second part contained the following methods: the Person-Supervisor Fit Scale, Proactive Behavior Scale, and Unethical Behavior Scale. The surveys were distributed by a group of research assistants who examined a group of employees from pre-determined sector. Participation in the study was voluntary and anonymous. The respondents were informed in a very general way about the purpose of the study and the rules for participation. They provided at least verbal consent to participate in the study.

${ }^{1}$ Calculated on the basis of the A-Priori Sample Size Calculator for Multiple Regression (Soper, 2019a). The assumptions: desired power level $=.8 ; \alpha=.05$; a small effect size is anticipated (Cohen's $\mathrm{f}^{2}=0.02$, based on literature (Zhang et al., 2012)). 


\section{Measures}

Person-Supervisor Fit Scale $(\alpha=.76)$. The construct was measured on a 12-item scale developed by Korulczyk (2016). The items were measured on a 5 -point Likert scale $(1=$ strongly disagree to $5=$ strongly agree $)$. The method is based on the theory of complementary and supplementary fit (Caplan, 1987) and synthetical model of person-organization fit (Kristof, 1996). The tool contains three factors, one for supplementary fit (SF; $\alpha=.78)$ and two for complementary demands-abilities fit (CMDAF; $\alpha=.76$ ) and needs-resources fit (CMNRF; $\alpha=.78$. On the basis of eigenvalues greater than one, the Explanatory Factor Analysis (EFA; $\mathrm{n}=202$ ) identified the three-factorial structure of the tool, which explained the $72 \%$ of common variance. Construct validity was supported by Confirmatory Factor Analysis $(\mathrm{CFA})^{2}$ on this sample $(n=328): \chi^{2}(54)=$ $=130.73, \chi^{2} / d f=2.42 ; p<.000 ;$ RMSEA $=.066$; CFI $=.915$. SF included following statements: "I think I share similar values to my supervisor," "I think I fit in with my manager," and "I think I'm like my boss." CMDAF included the following statements: "I can meet the demands of my manager," "I present the knowledge my superior expects me to have," "I feel like I'm putting as much effort as my supervisor expects of me," and "The superior formulates his requirements according to my capabilities." CMDAF included the following statements: "The superior formulates his requirements according to my capabilities," "I'm satisfied with the responsibilities my boss has set me," and "My manager can meet my developmental needs."

Proactive behavior $(\alpha=.83)$. Proactive behavior was measured by the 8 -item Proactive Behavior Scale. Four of the items were taken from Ashford and Black (1996), while four other items were developed to measure listening, observation, positive framing, and networking Burke (2009). The method was adapted in Polish by Korulczyk (2016). It measures the spectrum of specific behaviors defined as proactive: feedback-seeking, information-seeking, networking, general socializing, positive framing, job change negotiation, and relationship-building with one's manager. The higher the score, the higher the proactive behavior. The items were measured on a 7-point Likert scale $(0=$ never to $6=$ always $)$ and on an alternative scale measuring the frequency of behavior $(1=$ several times a year or a month to $6=$ every day). EFA of a single-factor structure explained the $46 \%$ of common variance with factor loadings over .56 .

\footnotetext{
${ }^{2}$ The power of the model using Monte Carlo simulation equals 1.00.
} 
A sample statement is "You asked your manager for feedback on issues that are important to you."

Unethical behavior $(\alpha=.80)$. The construct was measured on a 5 -item scale developed by De Coninck (1992), in Polish adaptation of Korulczyk (2016). The tool measures the attitude of the respondent to unethical behavior of character appearing in the presented story. This attitude results from a direct assessment of the character's behavior and may be either favorable or unfavorable. EFA of a single factor structure explained the $56 \%$ of common variance with factor loadings over .58. First, the method illustrated a situation where a sales representative used an unethical selling technique which misled the customer as to the price of the product. In addition, the consequences of the salesperson's behavior were very serious as the customer in the story wanted to the recover lost money and pursued the case in court. It was stressed that the character is one of the best salespeople as an excuse for unethical behavior. After reading the story, the respondent had to respond to five items assessing the salesperson's behavior. The first four items clearly justified the character's behavior, while the last one (inverted) suggested that he or she should be severely punished. Respondents answered on a 7-point scale of 1 to $7(1=$ strongly disagree to $7=$ strongly agree). Sample items are "I feel that his behavior in the situation described was completely understandable" and "I think everyone makes mistakes, so he shouldn't be punished."

\section{RESULTS}

\section{Preliminary analysis}

To ensure the reliability of the results, data cleaning techniques were used. Given presented hypotheses, the data were checked for outliers using visual and quantitative methods (multivariate outliers' statistics for multiple linear regression, MLR). After a careful analysis of scatterplots with marked outliers, no influencial outliers were identified (Aguinis et al., 2013). No missing data were identified.

Harman's single-factor approach was used to test if the study is affected by Common Method Bias (CMB, Podsakoff et al., 2003). It requires that when including all studied variables in the unrotated explanatory factor analysis (EFA), one single factor should not appear as an optimal solution or when fixed, one factor should not explain most of the covariance in the independent and depend- 
ent variables. The current study is not biased by CMB as EFA extracted five factors over eigenvalue equals one but also explained $20 \%$ of common variance with a single factor. See Table 1.

Table 1. Descriptive Statistics and Intercorrelations Between Components of PS Fit, Proactive Behavior, and Unethical Behaviors

\begin{tabular}{|c|c|c|c|c|c|c|c|c|c|c|}
\hline & Variable & $M$ & $M_{\mathrm{SE}}$ & $S D$ & $\begin{array}{c}\text { Skew- } \\
\text { ness }\end{array}$ & $\begin{array}{l}\text { Kurto- } \\
\text { sis }\end{array}$ & 1 & 2 & 3 & 4 \\
\hline 1 & Supplementary fit & $\begin{array}{c}11.32 \\
{[10.93} \\
11.71]\end{array}$ & 0.20 & $\begin{array}{c}3.60 \\
{[3.34,3.84]}\end{array}$ & 0.11 & -0.32 & 1 & & & \\
\hline 2 & $\begin{array}{l}\text { Complementary } \\
\text { demands-abilities fit }\end{array}$ & $\begin{array}{c}16.22 \\
{[15.90} \\
16.53]\end{array}$ & 0.16 & $\begin{array}{c}2.91 \\
{[2.59,3.22]}\end{array}$ & -1.01 & 1.89 & $\begin{array}{c}.25^{* * *} \\
{[.15, .35]}\end{array}$ & 1 & & \\
\hline 3 & $\begin{array}{l}\text { Complementary } \\
\text { needs-supplies fit }\end{array}$ & $\begin{array}{c}13.98 \\
{[13.59} \\
14.36]\end{array}$ & 0.20 & $\begin{array}{c}3.53 \\
{[3.26,3.77]}\end{array}$ & -0.57 & -0.20 & $\begin{array}{l}.64^{* * *} \\
{[.58, .70]}\end{array}$ & $\begin{array}{c}.43^{* * *} \\
{[.33, .53]}\end{array}$ & 1 & \\
\hline 4 & Proactive behaviors & $\begin{array}{c}34.41 \\
{[33.52} \\
35.30]\end{array}$ & 0.46 & $\begin{array}{c}8.27 \\
{[7.67,8.83]}\end{array}$ & -0.01 & -0.35 & $\begin{array}{c}.23^{* * * *} \\
{[.12, .33]}\end{array}$ & $\begin{array}{c}.07^{* *} \\
{[-.04, .17]}\end{array}$ & $\begin{array}{l}.12^{* * *} \\
{[-.01, .23]}\end{array}$ & 1 \\
\hline 5 & Unethical behaviors & $\begin{array}{r}18.79 \\
{[18.00} \\
19.57]\end{array}$ & 0.40 & $\begin{array}{c}7.13 \\
{[6.63,7.59]}\end{array}$ & 0.13 & -0.50 & $\begin{array}{c}.01^{* * *} \\
{[-.10, .11]}\end{array}$ & $\begin{array}{c}-.13^{* * *} \\
{[-.24,-.02]}\end{array}$ & $\begin{array}{l}-.12^{* * *} \\
{[-.23, .00][}\end{array}$ & $\begin{array}{c}.07^{* *} \\
{[-.05, .18]}\end{array}$ \\
\hline
\end{tabular}

Note. Bootstrap-based $95 \%$ confidence intervals are in square brackets (10,000 bootstrap samples).

$N=328$. Skewness $\mathrm{SE}=.14$ and kurtosis $\mathrm{SE}=.27$.

$*_{p}<.05 .{ }^{* *} p<.01 . * * * p<.001$.

\section{Hypotheses testing}

Hypothesis 1 that person-supervisor supplementary fit is positively associated with proactive behavior has been supported. Hypothesis 2 that personsupervisor complementary fits are positively associated with proactive behavior has not been supported. Multiple linear regression was used to predict proactive behavior based on three types of PS fit (Table 2). 
Table 2. Multiple Linear Regression of Person-Supervisor Fit Components and Proactive Behavior

\begin{tabular}{|c|c|c|c|c|c|c|}
\hline Name & $B$ & $S E_{\mathrm{B}}$ & $\beta$ & $\beta_{\text {semipartial }}$ & $t$ & $p$ \\
\hline Intercept & 28.26 & 2.73 & & & 10.34 & .001 \\
\hline Supplementary fit & $\begin{array}{c}0.61 \\
{[0.29,0.93]}\end{array}$ & 0.17 & $\begin{array}{c}.26 \\
{[.12, .40]}\end{array}$ & $\begin{array}{c}.20 \\
{[.09, .31]}\end{array}$ & 3.70 & .001 \\
\hline $\begin{array}{l}\text { Complementary } \\
\text { demands-abilities fit }\end{array}$ & $\begin{array}{c}0.08 \\
{[-0.27,0.42]}\end{array}$ & 0.17 & {$[-.03$} & {$[-.02$} & 0.45 & .657 \\
\hline $\begin{array}{l}\text { Complementary } \\
\text { needs-supplies fit }\end{array}$ & $\begin{array}{c}-0.14 \\
{[-0.50,0.21]}\end{array}$ & 0.18 & $\begin{array}{c}-.06 \\
{[-.21, .09]}\end{array}$ & $\begin{array}{c}-.04 \\
{[-.14, .06]}\end{array}$ & -0.79 & .429 \\
\hline
\end{tabular}

Note. $F(3,327)=6.12, p<.001 ; R^{2}=.055 ; \mathrm{f}^{2}=0.058 .95 \%$ confidence intervals are in square brackets, and power equals .97 are based on the Post-Hoc Statistical Power Calculator for Multiple Regression (Soper, 2019b). Sensitivity analysis using $\mathrm{G}^{*}$ Power $(\mathrm{n}=328$, power $=.97, \alpha=.05)$, equals $\mathrm{f}^{2}=0.037$. Statistically significant $p$ values are in boldface.

The regression equation was significant $(F(3,306)=6.12, p<.001)$, with $R^{2}$ of .06. Proactive behavior is weakly and positively associated with supplementary fit $\left(\beta_{\text {semipartial }}=.20, p<.001\right)$, but is not significantly associated with any complementary fit type.

Hypothesis 3 that person-supervisor supplementary fit is negatively associated with unethical behaviors has not been supported. Hypothesis 4 that personsupervisor complementary fits are negatively associated with unethical behaviors has been partially supported. Multiple linear regression with entry method was also used to predict unethical behavior based on PS fit types (Table 3).

Table 3. Multiple Linear Regression of Person-Supervisor Fit types and Unethical Behavior

\begin{tabular}{|c|c|c|c|c|c|c|}
\hline Name & $B$ & $S E_{\mathrm{B}}$ & $\beta$ & $\beta_{\text {semipartial }}$ & $t$ & $p$ \\
\hline Intercept & 24.00 & 2.36 & & & 10.16 & .001 \\
\hline Supplementary fit & $\begin{array}{c}0.27 \\
{[-0.01,0.55]}\end{array}$ & 0.14 & {$\left[\begin{array}{c}.14 \\
{[-.01, .28]}\end{array}\right.$} & $\begin{array}{c}.10 \\
{[-.01, .20]}\end{array}$ & 1.88 & .062 \\
\hline $\begin{array}{l}\text { Complementary fit: } \\
\text { demands-abilities perspective }\end{array}$ & $\begin{array}{c}-0.23 \\
{[-0.52,0.07]}\end{array}$ & 0.15 & $\begin{array}{c}-.09 \\
{[-.21, .03]}\end{array}$ & $\begin{array}{c}-.08 \\
{[-.19, .03]}\end{array}$ & -1.51 & .133 \\
\hline $\begin{array}{l}\text { Complementary fit: } \\
\text { Needs-supplies perspective }\end{array}$ & $\begin{array}{c}-0.32 \\
{[-0.63,-0.02]}\end{array}$ & 0.16 & $\begin{array}{c}-.16 \\
{[-.31,-.01]}\end{array}$ & $\begin{array}{c}-.11 \\
{[-.21,-.01]}\end{array}$ & -2.07 & .039 \\
\hline
\end{tabular}

Note. $F(3,337)=3.42, p=.018 ; R^{2}=.031 ; \mathrm{f}^{2}=0.032 .95 \%$ confidence intervals outliers are in square brackets and power equals .78 are based on the Post-Hoc Statistical Power Calculator for Multiple Regression (Soper, $2019 b)$. Sensitivity analysis using $\mathrm{G}^{*}$ Power $(n=328$; power $=.80 ; \alpha=.05)$, equals $\mathrm{f}^{2}=0.018$. Statistically significant $p$ values are in boldface. 
A significant regression equation was found $(F(3,309)=3.42, p=.018)$, with $R^{2}$ of .03 . Surprisingy, unethical behavior is weakly and negatively associated only with complementary needs-supplies fit $\left(\beta_{\text {semipartial }}=-.11, p=.039\right)$.

\section{DISCUSSION}

Although research on proactive behavior indicates such antecedents as proactive personality but also perceived work environemnt variables such as job autonomy, supportive supervision as the most significant (Parker et al., 2006), person-environent fit factors, including person-organization fit, person-group and person-supervisor fit, are also considered to contribute to explanation of proactive behavior but their role is largely unexplored. There is a lack of research on the relationship between different types of PE fit and organizational behaviors in moderately individualistic cultures like Poland. For these reasons we decided to investigate these topic areas.

The present study tested four hypotheses on the relationship between PS fit types, proactive behavior and unethical behavior. Hypothesis 1 has been supported. Supplementary fit was positively related to proactive behavior. This is in line with literature reports that perceived person-supervisor similarity has an effect on the proactive behavior of an employee. However, the existing literature supports the existence of PS supplementary fit - proactive behavior in relation to highly collectivist cultures (South Korea: Kim \& Kim, 2013; China: Zhang et al., 2012). Our study confirms the existence of this relationship in relation to the culture of a post-communist country with a cultural profile described as moderate individualism (Hofstede, 2020; GLOBE, 2020).

In contrast, Hypothesis 2 regarding complementary fits has been supported. Neither demands-abilities fit nor needs-supplies fit are related to proactive behavior. It means that whether or not employees perceive their work-related needs are satisfied, it will not translate into more proactive behavior of them. In the light of job demands-resources theory (Bakker \& Demerouti, 2007), it can be noted that neither resources nor demands play any role in the prediction of person's explicit proactivity but rather engagement and performance (Wang et al., 2017). Indeed, research related to job demands-resources theory on which the complementary fit is based, focus largely on the negative effects of imbalances between requirements and resources like burnout, depression, lack of work egnagement (Hakanen et al., 2008), which may indicate that work demands 
and resources are not a direct mechanism to explain positive organizational behaviors.

Hypothesis 3 has not been supported. Surprisingly, supplementary fit is not related with the unethical behavior. The perceived similarity between the superior and the subordinate does not translate into reduced unethical behavior of the employee. Unlike what we expected, moral competence is not the opposite phenomenon of unethical behavior, therefore the assumption of a negative relationship between PS supplementary fit and unethical behavior was false. The result may also be the consequence how unethical behavior was measured. The imaginary attitude to the presented unethical situation was measured rather than the real unethical behavior (e.g., actual misconduct) that occurred, which could have made the respondents less reserved in their assessments.

Interestingly, complementary demands-abilities fit is not related to unethical behavior. Formulating inadequate requirements to the employee's capabilities, expressed for example in workload, might not translate into employee attitutde towards unethical situations. Although research shows that higher supplementary fit may result in better communication and understanting of employee expectations and capabilities, in the opposite situation when these requirements are inadequate, a more gracious assessment of the unethical behavior of their colleagues, with the assumption also a higher risk of unethical behavior in the employee himself may simply not appear. In their research Andreoli and Lefkowitz (2009) showed that mostly organizational not personal factors, like formal organizational compliance practices and ethical climate, were independent predictors of misconduct. The other studies show that risk of unethical behavior is associated with moral traits, honesty, compassion, and fairness (Woo Jin \& Winterich, 2013). Thus, we conclude demands-abilities fit does not play any role in explanation of unethical behavior decision-making.

Subsequently, complementary needs-supplies fit is weakly and negatively associated with the unethical behavior. Perceived satisfaction of the follower's needs results in more negative assessment of unethical behavior of others. These results are in line with the ethical decision making theory (Ferrell \& Gresham, 1985), where the authors pointed out that one of the factors increasing the risk of unethical behavior are the values and attitudes possessed by the employee but also the values and attitudes of members of the person's social group like supervisor. The employees' attitude to their workplace, the superiors and the organization is directly related to its ability to meet the employees' needs and the ability to balance demands and resources theory (Bakker \& Demerouti, 2007). Thus, we 
conclude that needs-supplies fit does play a minor role in explaining unethical behavior decision-making.

In conclusion, PS supplementary fit is related to proactive behavior. PS complementary demands-abilities fit is not related to any of mentioned-above behaviors. It seems that this type of fit plays no significant role in the occurrence of these behaviors, while PS complementary needs-supplies fit little explains unethical behavior decision-making.

\section{LIMITATIONS}

The current study has its limitations. First, the cross-sectional design implies that the conclusions drawn from the study have a low degree of certainty as to the knowledge obtained and should be repeated on the Polish population. Unfortunately, practical problems such as the legal and business rationales for data protection have made it very difficult to access a sample that could be tested longitudinally.

Second, it would be worthwhile to research fit and performance measured more objectively, for example, as actual fit or work volume or the quality of subordinates' work. I decided to use perceptions as a measure of fit as they are more proximal predictor of individual outcomes (Cable \& Judge, 1996; Edwards et al., 1998). Nuttin claimed that we are acting on the reality we perceive (Zaleski, 1983). Thus I feel that perceived fit better fits into the current research scheme.

Third, unethical behavior was measured as people's attitudes towards a moral transgression committed by an imaginary individual. Although it is quite common in literature, it is a very specific conceptualization of unethical behavior, which should be considered during interpretation of the results, otherwise there is a risk of low ecological validity of the results. We followed this concern and we have been careful in interpreting the results. ${ }^{3}$

\section{THEORETICAL AND PRACTICAL IMPLICATIONS}

The study contributes and has some important implications for the domain of organizational theory and research on topic areas of person-supervisor fit, and it's outcomes. First, the study provided evidence that a person-organization fit

\footnotetext{
${ }^{3}$ We thank the reviewer for that comment.
} 
framework proposed by Kristof (1996) can be successfully extrapolated to its lower level conceptualisation, that is, person-supervisor fit. Second, both supplementary fit and complementary fit are constructs which correspond in various way to outcome variables as proactive behavior and unethical behavior, and generally the obtained pattern of results is consistent with other literature reports. Third, the study is one of the first conducted on a Polish population, which due to its cultural and historical background has a specific social and organizational structure, characterised by a strong hierarchization of relations in the organization and, on the other hand, by a high individualism of subordinates. This has an impact on structure of perceived fit to the superior.

We also believe that the study has valuable practical implications. First, it seems like needs-supplies fit might, in some situations, result in a reduction in productivity of employees but at the same time, reduces the risk of leaving the organization. This is worth pointing out to individuals managing organizations; also particular attention should be paid to those resources that reduce motivation to work productively by meeting needs. Second, it seems that attracting people (in an organization) who are like their supervisors may not be an effective method of increasing the global efficiency of the whole workplace.

\section{REFERENCES}

Aguinis, H., Gottfredson, R. K., \& Joo, H. (2013). Best-practice recommendations for defining, identifying, and handling outliers. Organizational Research Methods, 16(2), 270-301. https://doi.org/10.1177/1094428112470848

Ajzen, I., \& Fishbein, M. (1980). Understanding attitudes and predicting social behavior. Retrieved from https://pdfs.semanticscholar.org/0e84/1ed289a3cf9b9a799da4b344bd93975 42c2e.pdf

Andreoli, N., \& Lefkowitz, J. (2009). Individual and organizational antecedents of misconduct in organizations. Journal of Business Ethics, 85(3), 309.

Ashford, S. J., \& Black, J. S. (1996). Proactivity during organizational entry: The role of desire for control. Journal of Applied Psychology, 81(2), 199-214.

Bakker, A. B., \& Demerouti, E. (2007). The job demands-resources model: State of the art. Journal of Managerial Psychology, 22(3), 309-328. https://doi.org/10.1108/02683940710733115

Bateman, T. S., \& Crant, J. M. (1993). The proactive component of organizational behavior: A measure and correlates. Journal of Organizational Behavior, 14(2), 103-118. https://doi.org/10.1002/job.4030140202

Brudek, P., Korulczyk, T., \& Korulczyk, N. (2018). Spouses' fit and Marriage Satisfaction in Late Adulthood. Roczniki Psychologiczne, 21(1), 69-85. https://doi.org/10.18290/rpsych.2018.21.1-5

Burke, S. E. (2009). Proactive Socialisation: A longitudinal investigation of newcomer adjustment inside both an institutionalised and individualised workplace (Unpublished doctoral dissertation). Victoria University of Wellington, Wellington. 
Byrne, D. E. (1971). The attraction paradigm (Vol. 11). Academic Press.

Cable, D. M., \& Judge, T. A. (1996). Person-organization fit, job choice decisions, and organizational entry. Organizational Behavior and Human Decision Processes, 67(3), 294-311.

Caplan, R. D. (1987). Person-environment fit theory and organizations: Commensurate dimensions, time perspectives, and mechanisms. Journal of Vocational Behavior, 31, 248-267. https://doi.org/10.1016/0001-8791(87)90042-X

Crant, J. M. (2000). Proactive behavior in organizations. Journal of Management, 26(3), 435-462. https://doi.org/10.1177/014920630002600304

Czerw, A., \& Czarnota-Bojarska, J. (2016). Dopasowanie człowiek-środowisko i postawa wobec pracy jako motywatory zachowań organizacyjnych [Person-environment fit and attitude to work as motivators of organizational behavior]. Psychologia spoleczna, 1, 8-19.

Dalal, R. S. (2005). A meta-analysis of the relationship between organizational citizenship behavior and counterproductive work behavior. Journal of Applied Psychology, 90(6), 12411255.

De Coninck, J. B. (1992). How sales managers control unethical sales force behavior. Journal of Business Ethics, 11(10), 789-798. https://doi.org/10.1007/BF00872311

Edwards, J. R. (1991). Person-job fit: A conceptual integration, literature review, and methodological critique. In C. Cooper (Ed.), International review of industrial and organizational psychology (pp. 283-357). John Wiley \& Sons.

Edwards, J. R., Caplan, R. D., \& Harrison, R. V. (1998). Person-environment fit theory: Conceptual foundations, empirical evidence, and directions for future research. In C. L. Cooper (Ed.), Theories of organizational stress (pp. 28-67). Oxford University Press.

Endler, N. S., \& Magnusson, D. (1976). Toward an interactional psychology of personality. Psychological Bulletin, 83(5), 956-974.

Ferrell, O. C., \& Gresham, L. G. (1985). A contingency framework for understanding ethical decision making in marketing. Journal of Marketing, 49(3), 87-96. https://doi.org/10.2307/ 1251618

Frese, M., \& Fay, D. (2001). Personal initiative: An active performance concept. Research in Organizational Behavior, 23, 133-187. https://doi.org/10.1016/S0191-3085(01)23005-6

Hakanen, J. J., Schaufeli, W. B., \& Ahola, K. (2008). The job demands-resources model: A threeyear cross-lagged study of burnout, depression, commitment, and work engagement. Work \& Stress, 22(3), 224-241.

Hammond, M. M., Neff, N. L., Farr, J. L., Schwall, A. R., \& Zhao, X. (2011). Predictors of individual-level innovation at work: A meta-analysis. Psychology of Aesthetics, Creativity, and the Arts, 5(1), 90-105.

Hunt, S. D., \& Vitell, S. (1986). A General Theory of Marketing Ethics. Journal of Macromarketing, 6(1), 5-16. https://doi.org/10.1177/027614678600600103

Karassavidou, E., \& Glaveli, N. (2006). Towards the ethical or the unethical side? An explorative research of Greek business students' attitudes. International Journal of Educational Management, 20(5), 348-364.

Kim, T. Y., \& Kim, M. (2013). Leaders' moral competence and employee outcomes: The effects of psychological empowerment and person-supervisor fit. Journal of Business Ethics, 112(1), 155-166. https://doi.org/10.1007/s10551-012-1238-1 
Korulczyk, T. (2016). Dopasowanie $w$ relacji przełożony-podwładny, retencja $i$ wydajność pracy [Supervisor-subordinate fit, retention, and job performance] (Unpublished doctoral dissertation). John Paul II Catholic University of Lublin, Lublin, Poland.

Korulczyk, T., \& Korulczyk, N. (2018). The role of fit theories in job analysis. In A. Biela (Ed.), European Questionnaire for Job Analysis (EQJA): Theoretical and methodological bases (pp. 65-85). Peter Lang.

Kristof-Brown, A. L., \& Billsberry, J. (2013). Organizational fit: Key issues and new directions. John Wiley \& Sons.

Kristof-Brown, A. L., Zimmerman, R. D., \& Johnson, E. C. (2005). Consequences of individuals' fit at work: A meta-analysis of person-job, person-organization, person-group, and personsupervisor fit. Personnel Psychology, 58(2), 281-342. https://doi.org/10.1111/j.17446570.2005.00672.x

Kristof, A. L. (1996). Person-organization fit: An integrative review of its conceptualizations, measurement, and implications. Personnel Psychology, 49(1), 1-49. https://doi.org/10.1111/ j.1744-6570.1996.tb01790.x

Laszlo, E. (1996). The Systems View of the World: The Natural Philosophy of the New Developments in Science (2nd ed.). Retrieved November 16, 2019, from http://search. proquest.com/openview/d373481c1e03d1111dac1876243426ce/1?pqorigsite $=$ gscholar $\& \mathrm{cbl}=1817765$

Lewin, K., Adams, D. K., \& Zener, K. E. (1935). A dynamic theory of personality. McGraw-Hill.

Llorens, S., Bakker, A. B., Schaufeli, W., \& Salanova, M. (2006). Testing the robustness of the job demands-resources model. International Journal of Stress Management, 13(3), 378-391. doi: $10.1037 / 1072-5245.13 .3 .378$

Locke, E. A. (1976). The nature and causes of job satisfaction. In M. Dunnette (Ed.), Handbook of industrial and organizational psychology (pp. 1297-1350). Rand McNally.

McNeill, S. (2019). The cost of unethical behavior. Retrieved November 17, 2019, from https://assets.corporatecompliance.org/Portals/1/PDF/Resources/ethikos/pastissues/2014/scce-2014-03-ethikos-mcneill.pdf

Meglino, B. M., \& Ravlin, E. C. (1998). Individual values in organizations: Concepts, controversies, and research. Journal of Management, 24(3), 351-389.

Oh, I. S., Guay, R. P., Kim, K., Harold, C. M., Lee, J. H., Heo, C. G., \& Shin, K. H. (2014). Fit happens globally: A meta-analytic comparison of the relationships of person-environment fit dimensions with work attitudes and performance across East Asia, Europe, and North America. Personnel Psychology, 67(1), 99-152.

O'Reilly, C. A., Chatman, J., \& Caldwell, D. F. (1991). People and organizational culture: A profile comparison approach to assessing person-organization fit. Academy of Management Journal, 34(3), 487-516.

Parker, S. K., Bindl, U. K., \& Strauss, K. (2010). Making things happen: A model of proactive motivation. Journal of Management Online First, 36(4). https://doi.org/10.1177/014920 6310363732

Parker, S. K., \& Collins, C. G. (2010). Taking stock: Integrating and differentiating multiple proactive behaviors. Journal of Management, 36(3), 633-662. https://doi.org/10.1177/0149 206308321554

Parker, S. K., Williams, H. M., \& Turner, N. (2006). Modeling the antecedents of proactive behavior at work. https://doi.org/10.1037/0021-9010.91.3.636

Parsons, F. (1909). Choosing a vocation. Houghton Mifflin. 
Podsakoff, P. M., MacKenzie, S. B., Lee, J. Y., \& Podsakoff, N. P. (2003). Common method biases in behavioral research: a critical review of the literature and recommended remedies. Journal of Applied Psychology, 88(5), 879-903. https://doi.org/10.1037/0021-9010.88.5.879

Rice, R. W., McFarlin, D. B., Hunt, R. G., \& Near, J. P. (1985). Organizational work and the perceived quality of life: Toward a conceptual model. Academy of Management Review, 10, 296-310.

Ruiz-Palomino, P., \& Martínez-Cañas, R. (2014). Ethical culture, ethical intent, and organizational citizenship behavior: The moderating and mediating role of person-organization fit. Journal of Business Ethics, 120(1), 95-108. https://doi.org/10.1007/s10551-013-1650-1

Saks, A. M., Gruman, J. A., \& Cooper-Thomas, H. (2011). The neglected role of proactive behavior and outcomes in newcomer socialization. Journal of Vocational Behavior, 79(1), $36-46$.

Saks, A. M., Taggar, S., \& Ashforth, B. E. (2004). A self-regulatory conceptualization of newcomer proactive socialization. Paper presented at the annual meeting of the Society for Industrial and Organizational Psychology. Chicago.

Schneider, B. (1987). The people make the place. Personnel Psychology, 14, 437-453.

Schneider, B., Kristof-Brown, A. L., Goldstein, H. W., \& Smith, D. B. (1999). What is this thing called fit? In N. Anderson \& P. Herriot (Eds.), International Handbook of Selection and Assessment (pp. 393-413). John Wiley \& Sons.

Schwab, D. P. (1980). Construct validity in organizational behavior. In B. Cummings \& M. Staw (Eds.), Research in organizational behavior (pp. 3-43). JAI Press.

Seong, J. Y., Kristof-Brown, A. L., Park, W. W., Hong, D. S., \& Shin, Y. (2015). Person-group fit: Diversity antecedents, proximal outcomes, and performance at the group level. Journal of Management, 41(4), 1184-1213. https://doi.org/10.1177/0149206312453738

Smith, M. A. (2002, April). Subordinate-supervisor "fit" using the Big Five personality constructs. Paper presented at the 17th Annual Conference of the Society for Industrial and Organizational Psychology. Toronto, Canada.

Soper, D. S. (2019a). A-priori sample size calculator for multiple regression [Computer software]. Retrieved November 5, 2019, from https://www.danielsoper.com/statcalc

Soper, D. S. (2019b). Post-hoc sample size calculator for multiple regression [Computer software]. Retrieved November 5, 2019, from https://www.danielsoper.com/statcalc

Thomas, J. P., Whitman, D. S., \& Viswesvaran, C. (2010). Employee proactivity in organizations: A comparative meta-analysis of emergent proactive constructs. Journal of Occupational and Organizational Psychology, 83(2), 275-300.

Turban, D. B., \& Jones, A. P. (1988). Supervisor-subordinate similarity: Types, effects, and mechanisms. Journal of Applied Psychology, 73(2), 228-234. https://doi.org/10.1037/00219010.73.2.228

Turban, D. B., \& Keon, T. L. (1993). Organizational attractiveness: An interactionist perspective. Journal of Applied Psychology, 78(2), 184-193.

Von Bertalanffy, L. (1968). General system theory: Foundations, development, applications. George Braziller.

Wang, Z., Zhang, J., Thomas, C. L., Yu, J., \& Spitzmueller, C. (2017). Explaining benefits of employee proactive personality: The role of engagement, team proactivity composition and perceived organizational support. Journal of Vocational Behavior, 101, 90-103. https://doi.org/10.1016/j.jvb.2017.04.002 
Wayne, S. J., \& Liden, R. C. (1995). Effects of impression management on performance ratings: A longitudinal study. Academy of Management Journal, 38(1), 232-260.

Woo Jin, C., \& Winterich, K. (2013). Can brands move in from the outside? How moral identity enhances out-group brand attitudes. Journal of Marketing, 77(2), 96-111. Retrieved from http://www.marketingpower.com

Zaleski, Z. (1983). Nuttina koncepcja ludzkiej motywacji [Nuttin's concept of human motivation]. Roczniki Filozoficzne, 31(4), 219-246.

Zhang, Z., Wang, M., \& Shi, J. (2012). Leader-follower congruence in proactive personality and work outcomes: The mediating role of leader-member exchange. Academy of Management Journal, 55(1), 111-130. https://doi.org/10.5465/amj.2009.0865 